\title{
Air Modal Perishable Cargo Dispatch: \\ Case Study of a Sustainable Proposal Assisted by Process Modelling and Simulation
}

\author{
Lucas Magno Resende Coelho ${ }^{1}$, Reubert Fernandes Rodrigues Barbosa ${ }^{1}$, Ramon Cleiton \\ Teodoro Silva ${ }^{1}$, Luiz Melk de Carvalho ${ }^{1}$ and Flávio Henrique Batista de Souza ${ }^{1, *}$ \\ ${ }^{1}$ Centro Universitário de Belo Horizonte - UNIBH - Instituto de Engenharia e Tecnologia, Brazil. \\ *Corresponding author: flabasouza@yahoo.com.br
}

\begin{abstract}
.
The importance of perishable transport is clearly observed in research to agile logistic techniques and fragile cargos. This case study evaluates a project that considers a sustainable option for cooling perishable fillers using Polyethylene Terephthalate bottles (PET bottles) as cooling elements. The analysis was supported by modeling and simulation technologies based on stochastically timed Petri nets for strategic management of the material supply chain (boxes and PET bottles) for the air modal dispatch process. The optimization process of this straightforward method was submitted to more than 10,500 dispatches of perishable cargo in a logistics operator from Minas Gerais (Brazil) and was considered the evaluation of the following parameters during this study: temperature variation, delivery time and compliance with customer requirements. As most prominent results, there is a dispatch methodology that yielded a monthly saving of more than $\mathrm{R} \$ 36,000$ (Brazilian reais) and an open-source tool for supply chain simulation. The simulations were able to evaluate the supply of raw material for the process based on PET bottles for a horizon of approximately 2 years, allowing the forecast of unmet demands, and identify which shortages caused the process interruption.
\end{abstract}

Keywords: Perishable Cargos, Sustainable, Air Modal, Stochastically Timed Petri Nets, Supply Chain.

\section{Introduction}

The process of dispatching perishable cargo by air mode is a matter of high relevance in several aspects, such as: care with the materials, price of the elements involved, replenishment and time of operations (due to the type of element transported). In a general context, as already stated in the literature, logistics is treated as the process of localization, transportation, among other factors behind a given product, encompassing its entire process from its raw material to the final state where it will be made available to the customers. Worked logistics are based on air modal, and there are several factors that make air transport to have a higher 
cost, such as: fuel, maintenance, labor, among others. This logistic mode has advantages (i.e. delivery speed, distance achieved, safety) and disadvantages (i.e. the physical dimensions of aircraft transport holds, freight cost, collection and delivery times and ground handling) (Novaes, 2016).

This present research, that began in 2017 (with works already published and defended by (Silva, 2017) and (Silva et al, 2017)), demonstrates the complete process of an approach that includes: understanding a perishable cargo dispatch process; optimizing the flow of activities through the use of a sustainable PET bottle-based process (which has made the process 4 times cheaper for the logistics operator) and; finally, the development of a simulator, based on stochastically timed Petri nets, to analyse supply scenarios for strategic management of the logistics operator. Thus, the aim of this paper is to demonstrate these three stages and their consequences in a real company in a city of Minas Gerais (Brazil).

This work is justified by the demand of process optimization for constant updating of companies, the feasibility of using techniques that present sustainable characteristics, cost reduction in relation to the transported loads, and the fact that a simulation analysis can help the process of decision-making without material costs or damage.

This paper is organized as follows: in section 2, the project references are presented; Section 3 presents the methodologies used; In the fourth section the results are demonstrated and in the fifth section the conclusion of the research.

\section{Materials and Methods}

\subsection{Reference Process}

The flowchart presented in Fig. 1 demonstrates the operational phases of air cargo transportation required by the ANAC - Agência Nacional de Aviação Civil. It displays the loading process. Through it, the phases are analysed in order to identify possible problems and difficulties with the shipment. Shipping is very bureaucratic, and any problem at any of these stages could lead to delays (ANAC, 2013). It is noticed that after going through some tasks within the operational phase flowchart (Fig. 1), there is a flowchart of the procedures required by ANAC (Fig. 2).

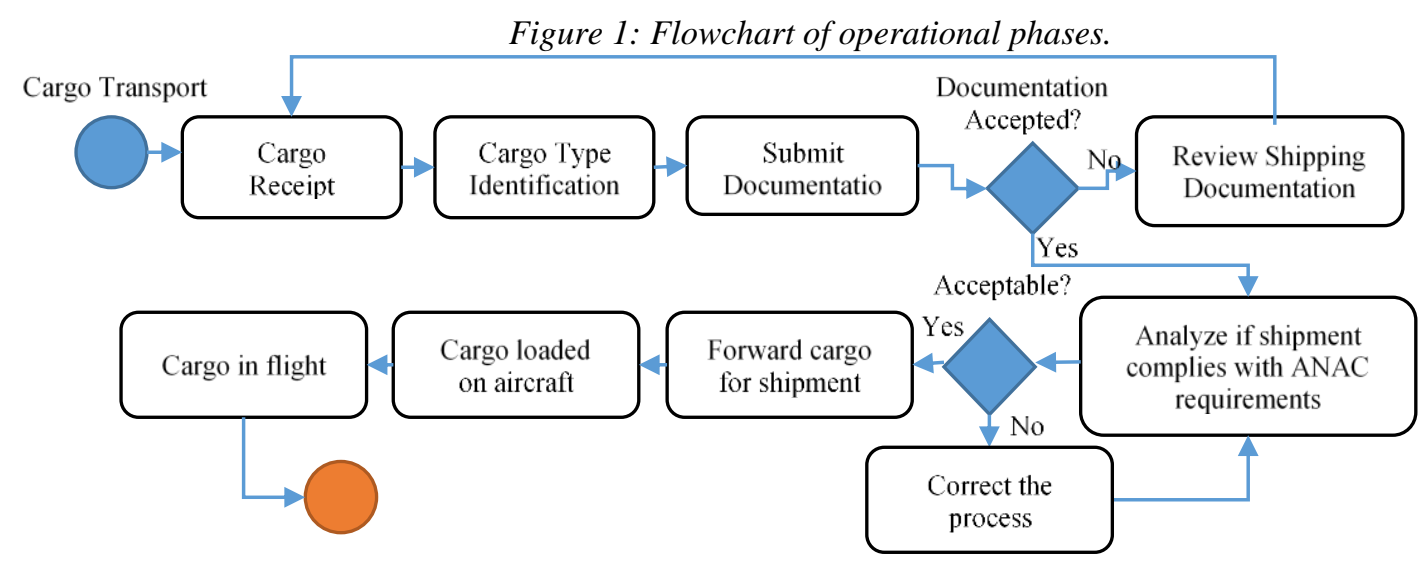

Source: (Authors, 2019) 
This is the flow for the project in question, which it is the transport of perishable cargo by air transport mode. The flowchart ranges from cargo receipt to cargo tracking and traceability. The flow is responsible for maintaining the quality in the transport of these perishable cargo so that they reach the end consumer with the required quality. After the packing process, the loads are evaluated by ANAC, if there is a problem that goes beyond the established quality standards, it is mandatory to restart the flow.

Figure 2: Flowchart of procedures required by ANAC.

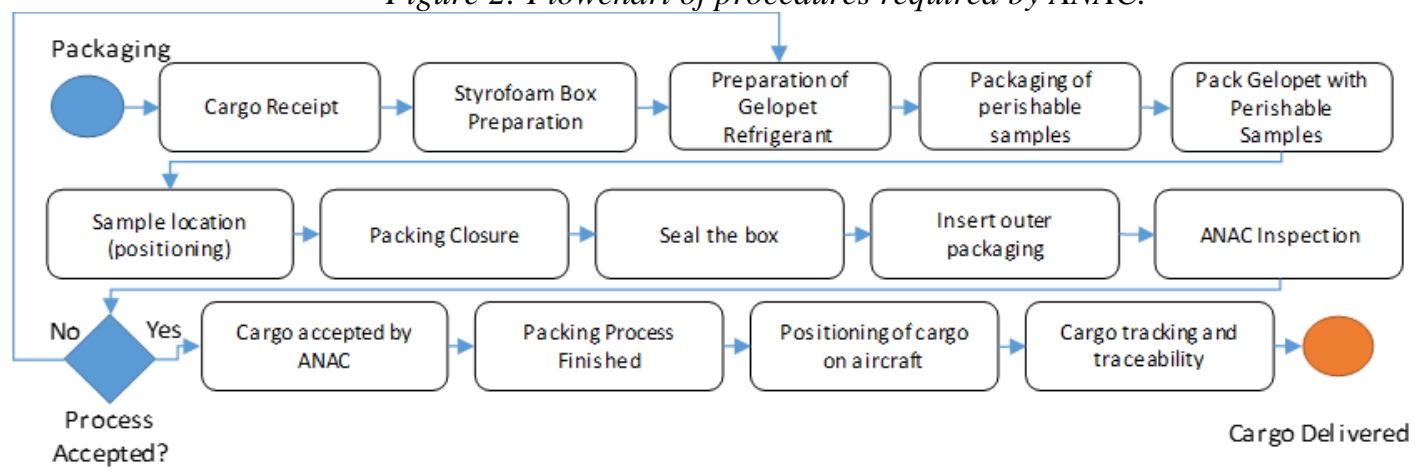

Source: (Authors,2019)

\subsection{Stochastically Timed Petri Nets}

According to Cassandras and Lafortune (2008), the Petri net consists of a system specification technique, which has several analysis mechanisms and can be represented mathematically. It has several applications in information systems (Sakurada \& Miyake, 2009), logistics, transportation, process optimization (Reis et al, 2018) among others (Lisboa et al, 2019). It consists of a directed, split graph containing state nodes (places $P$ ) and event nodes (transitions $T$ - if this element is black, there is no timeout; if blank, a deterministic or stochastic timeout, must be waited for firing) where they are interconnected by means of oriented segments, the arcs $A$, thus representing the flow between states and events. A state is represented by circles and can have one or more tokens (marks that represent the existence or otherwise of a resource) (Wang, 1998). The transitional nodes are represented by rectangles. A mark-up vector is an event of a simulation table, containing the simulation data. In the case of Fig. 3, the marking vector $\mathrm{x}$ contains the number of tokens in each place, in the case $x=[1$ $0]$.

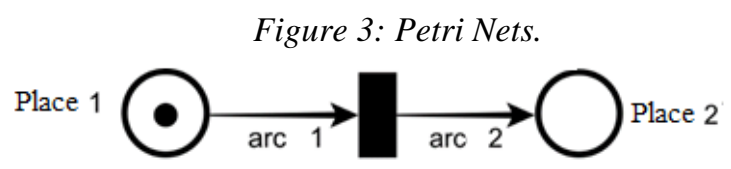

Source: (Authors,2019)

As demonstrated by Wang (1998), it is possible take as reference the definition: "A stochastic timed Petri net (STPN) is a Petri net with a set of specifications for computing the distributions $F(i, x \mid M, Z)$, and with an initial probability distribution". Thus, with the definition presented it is possible to assume that STPNs can be used in projects where the distributions are not necessarily exponential, as in the design of this paper. 


\subsection{Experimental Methods}

This case study is guided by an experimental process based on 2 steps.

Step 1: Data collection (activities, resources used, time of each task) was performed, with the aid of process monitoring with Gelox (original process) based on the flowcharts of Fig. 1 and 2. Thus, the process optimization was implemented with the use of GeloPet (so-called the solution based on disposable PET type bottles), the process was analysed and the financial effects of such solution was verified.

Step 2: A modeling and simulation based on stochastically timed Petri nets was developed for stock simulation and replenishment of materials required for the solution developed in Step 2.

Financial assessments were made based on the the impacts of each model.

\section{Results and Discussions}

\subsection{Process Optimization via Gelopet}

The reference process is based on a study in which 14,000 perishable cargo shipment data were collected in 2017, where 10,500 were from air shipments. According to Silva et al (2017), most Brazilian companies that work with the transportation of perishable samples, face difficulties due to the procedures required by the airlines related to their transportation, which causes high expenses in the adequacy of the cargo to achieve the required use. The triple Pack and Gelox, (a hard reusable ice used in place of the common ice for sample transport - Fig. 4 (a)), presents the following positive points: it remains in its solid state longer than ice, does not wet thaw because it is a non-toxic gel, while, Gelopet (Fig. 4 (b)) consists of the use of disposable ice bottles to cool the samples, and these bottles are capped by Styrofoam to prevent their displacement.

Figure 4: Gelox versus Gelopet.

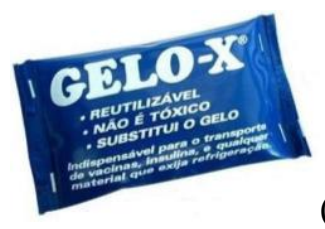

(a)

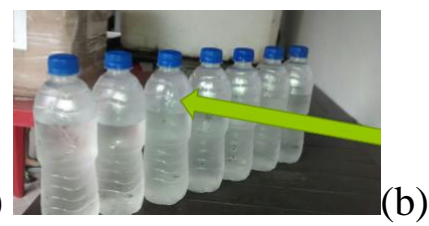

Source: (Authors,2019)

This first stage of research, explored in a short way, has been briefly presented in Silva et al (2017) and is further detailed in this article. An important fact is that the price of using a PET bottle is a quarter of the price of a Gelox pack. In the optimized system, two individual plastic bags are used to separate Gelopet from the sample, thus preventing leakage.

The positioning of the samples is done in the closed center with bags, and the Gelopet on the sides to perform temperature control.

In addition to training with the team, analysis and experiments were conducted regarding:

Temperature: Samples should be transported at a temperature of 12 degrees Celsius. In some cases, ice water may not be used, as leakage may occur during the 24-hour journey, making it a critical item for a short time of validation. In the graph, in Fig. 5, one can identify the 
average temperature in the collection and delivery, the variation, or temperature loss during the journey.

Figure 5: Temperature variation in dispatch processes in 2017

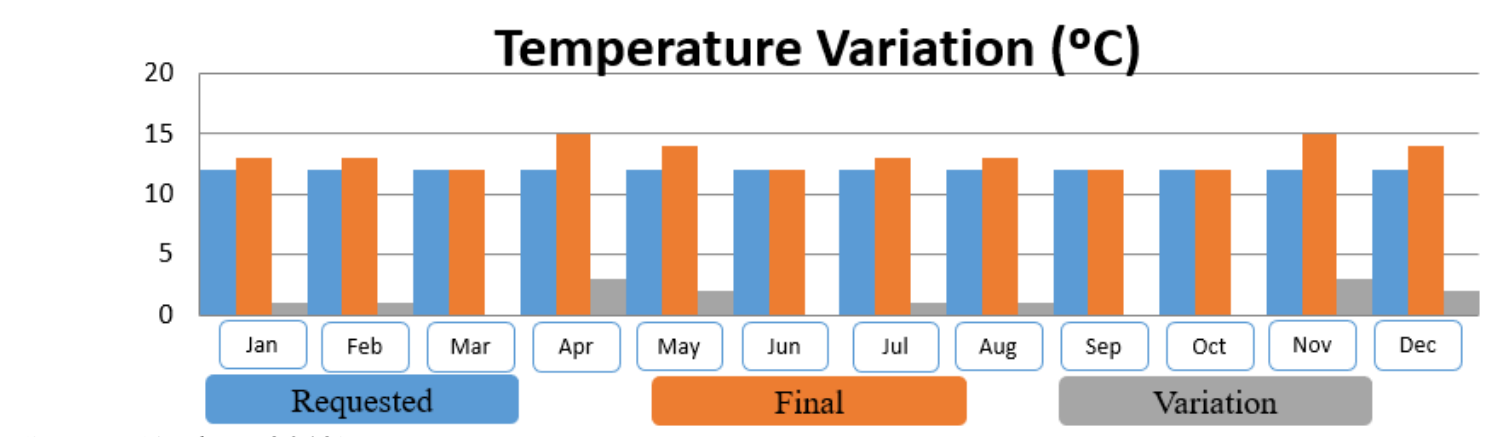

Source: (Authors, 2019)

Lead Time: The agreement with the laboratories for sample delivery time was 24 hours. The average delivery time was identified, and the average delivery time is 18 hours and 05 minutes, i.e. meeting customer requirements.

Preservation of biological characteristics and quality of samples: The quality of the samples depends on the ideal temperature, that is, there should be a stable cooling during boarding, as this material is transported in aircraft, this facilitates due to the low temperature in the holds during the flight. The customer has five requirements for their assessment, ranging from 0 to 5 , considering temperature, lead time, sample retention, packaging, and employee training, as shown in the graph in Fig. 6. Customers accept short delays because when dealing with urgent delivery times, 24 hours after the cargo is received by the logistics operator, the acceptable margin of delay is $10 \%$ and the temperature increase of up to $4 \%$, which is almost impossible to avoid due to various external factors.

Figure 6: Service Requirements Quality Chart in 2017.

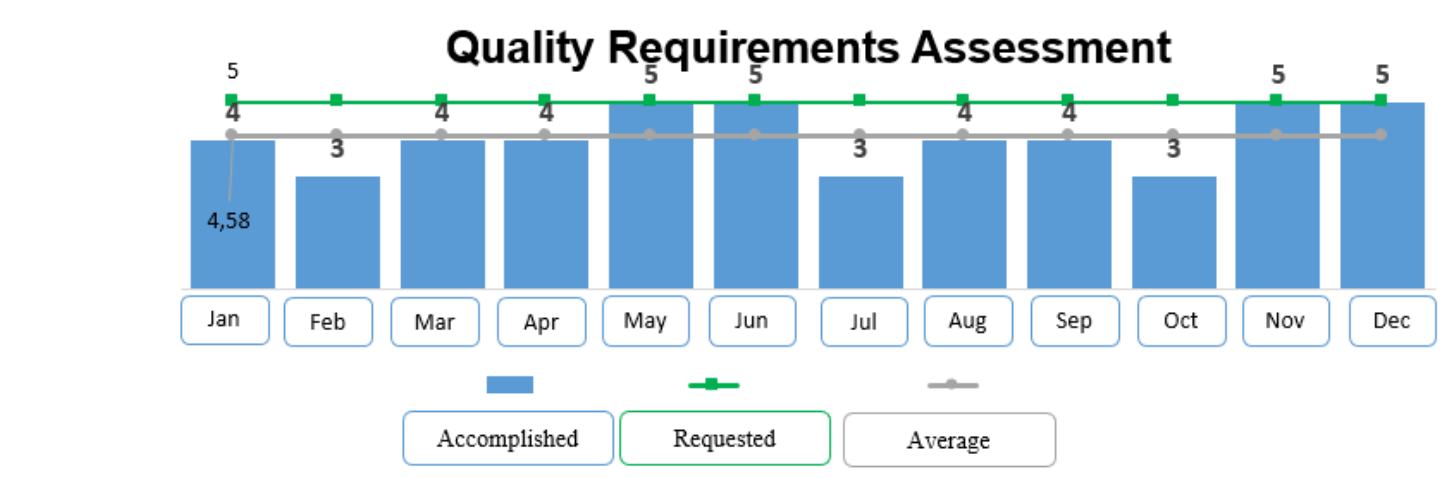

Source: (Authors, 2019)

The measures the company takes to prevent these problems from occurring are provide training and operating procedures. The savings generated by this process amount are up to approximately $\mathrm{R} \$ 36,000.00$ per month. 


\subsection{Modeling}

Fig. 7 demonstrates the modeling of the perishable cargo dispatching process in question, developed after the optimized process of section 3.1 is consolidated. In addition to simulating the dispatch process, it evaluates the supply of PET bottles for the optimized process. It should be noted that the proposed model refers to a Styrofoam package, called model 1. This package contains up to 8 Gelopets. For other box models, it is necessary to reevaluate elements such as: number of Gelopets, number of boxes in stock, frequency of orders that comply with the new box pattern, among other pertinent details. Tab. 1 has the average times of each activity. Transitions with "**" have a mean time of $\mu$ for an exponential distribution function.

In the Petri net there are three places $\mathrm{P}$ where loads are counted in different situations. The first is $\mathrm{P}=\{$ Cargos_counter $\}$ which counts the amount of loads received during the simulation (remembering that 1 load contains 4 samples). There is a second place $\mathrm{P}=\{$ Rework_Counter $\}$ which counts the number of cargos that have been reworked because they have been rejected by ANAC. The third one is $\mathrm{P}=\{$ Dispatched_cargos $\}$, which counts the number of shipments that were successfully dispatched. All three of these P seats can hold up to 10,000 load units. If any of these counters reaches the limit, the simulation ends.

Samples arrive one by one every 20 minutes at $\mathrm{T}=\{$ Receive_Samples $\}$. To assemble a package a quantity of 4 samples is required instead of $\mathrm{P}=\{$ Received_Samples $\}$. After the cargo-receiving action occurs (transition firing $\mathrm{T}=\{$ Receive_Cargo $\}$ ), it is stored in a warehouse where it can store up to 200 cargos. In parallel there is the process where the model 1 Styrofoam box is stored (where it is possible to see the number of boxes in stock at $\mathrm{P}=\{$ Bottles_for_gelopet_model_1 $\}$ - it has the capacity to store 1000 boxes).

Table 1: Firing times in minutes.

\begin{tabular}{|c|c|c|c|}
\hline Transition & time & Transition & time \\
\hline Receive_Samples & 20 & Stop_Lack_Boxes 1 & - \\
\hline Receive_Cargo & - & Stop_Lack_Boxes2 & - \\
\hline Prepare_Styrofoam_Box & 5 & Count_Days1 or 2 & 1440 \\
\hline Add_perishable_with_Protection & 3 & Continue & - \\
\hline Alocate_Refrigerant_Gelopet & 3 & Stop_Lack_Bottles1 & - \\
\hline Location_position_samples & 3 & Stop_Lack_Bottles2 & - \\
\hline Close_Box_model_1 & 1 & Restock_Bottles & 1440 \\
\hline Seal_Box & 1 & Refrigerate & 120 \\
\hline Insert_outer_packaging & 1 & ANAC_Inspection_Rejected $* *$ & $\mu=50$ \\
\hline ANAC_Inspection_Accepted $* *$ & $\mu=5$ & Rework_Fail ** & $\mu=18$ \\
\hline Packing_Process_Finished & - & ANAC_Inspection_Rejected_After_Rework** & $\mu=63$ \\
\hline Positioning_cargo_on_aircraft & 15 & Rework_Successed $* *$ & $\mu=18$ \\
\hline Cargo_tracking_traceability & - & ANAC_Inspection_Accepted_After_Rework** & $\mu=5$ \\
\hline
\end{tabular}




\begin{tabular}{|c|c|c|c|}
\hline Finish & - & Restock_Boxes & 1440 \\
\hline Source: (Authors,2019)
\end{tabular}

Right after these two processes, the samples are placed inside the Styrofoam box $(\mathrm{P}=\{$ Cargos_in_Styrofoam $\})$, where this process takes 5 minutes. The box is then wrapped with a protective cover (action that takes place by triggering transition $\mathrm{T}=\{$ Add_perishable_with_Protection $\}$ ), a process that takes 3 minutes. This process is justified in case the sample leaks, the tarpaulin can hold this leak and protect the other samples, as shown in Fig. 7.

After that the cargo, during the simulation, goes to the place $\mathrm{P}=\{$ Perishable_in_Structure $\}$, where it will be packed with the protection, waiting for the refrigerant element. To keep these elements cool, it must also place Gelopet inside the boxes. Assuming there is a stock of bottles for the Gelopets at $\mathrm{P}=\{$ Bottles_for_gelopet_model_1 $\}$, they are cooled with the freezer action, which lasts for 120 minutes (action which, when completed, will be symbolized by triggering the $\mathrm{T}=\{$ Refrigerate transition $\}$ ).

By triggering this transition, the Gelopet cooling element ready for use in $\mathrm{P}=\{$ Refrigerant_element_gelopet $\}$ is obtained. Eight Gelopets are allocated to each Model 1 box at T $=\{$ Alocate_Refrigerant_Gelopet $\}$ (as a rule, 2 Gelopets per sample) that lasts around 3 minutes to complete, generating a Model 1 structure with Gelopet, symbolized by the place $\mathrm{P}=\{$ Styrofoam_model_1_with_gelopet $\}$. 
10th International Conference on Research in

ENGINEERING, SCIENCE \& TECHNOLOGY

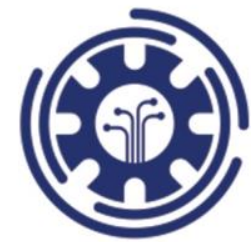

Rome, Italy

21-23 February 2020

Figure 7: Modeling of the dispatch process to aid the PET bottle supply chain

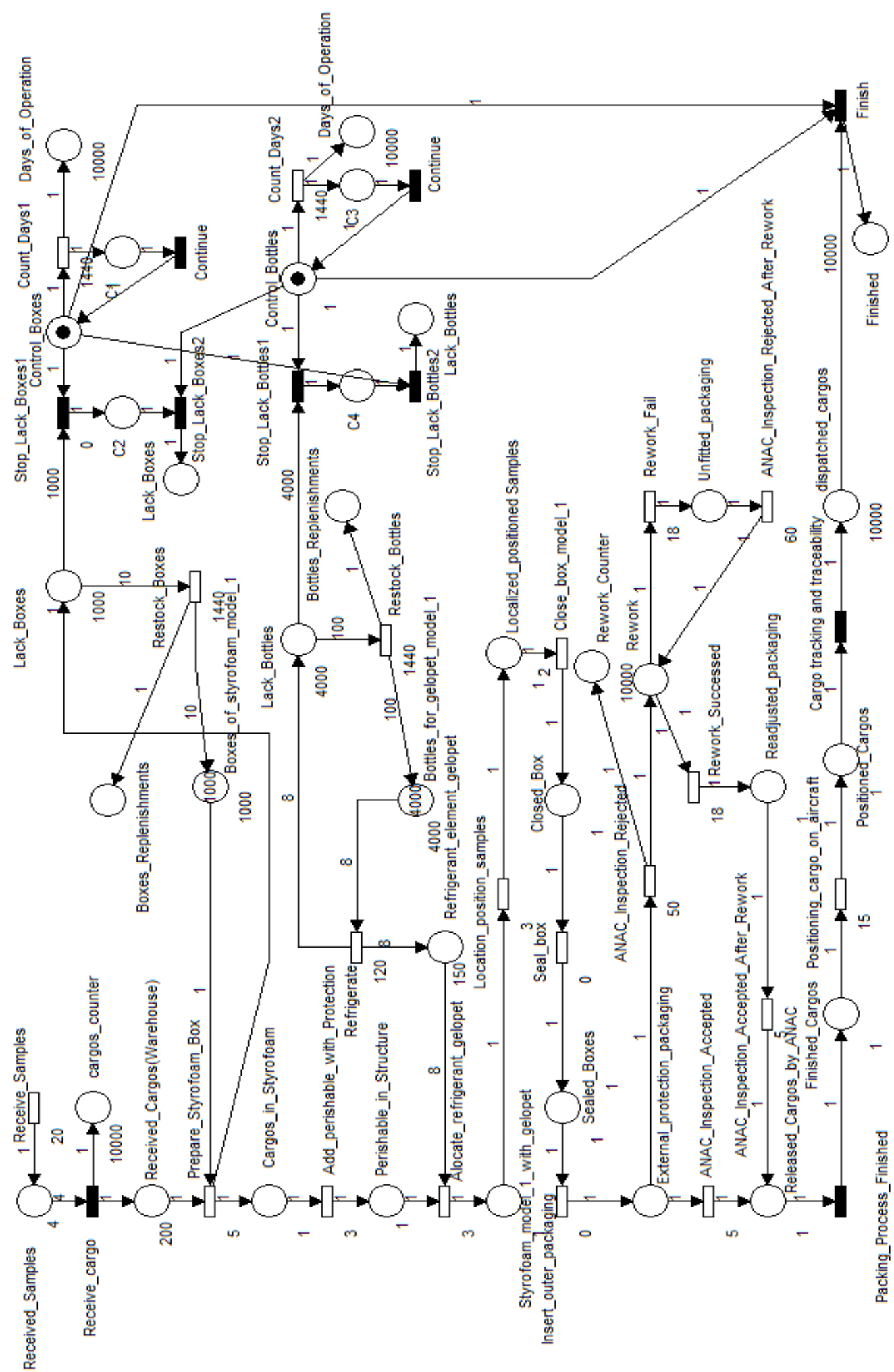

Source: (Authors, 2019) 
After the insertion of the Gelopets in the Styrofoam, along with the other elements, the sample placement and positioning step is performed, which takes 3 minutes to complete (a step that is of great importance in the process, since the elements packed are mutable, symbolized by $\mathrm{T}=\{$ Location_position_samples $\}$ ). After positioning the samples, there is the step of closing the package that takes 1 minute to complete, $T=\{$ Close_box_model_1 $\}$, then sealing that package, spending 3 minutes.

Then the cargo is sealed at $\mathrm{T}=\{$ seal_box $\}$ and takes 1 minute. After a package is inserted outside the load, this procedure also takes 1 minute. After these procedures it is necessary to insert an outer packaging, symbolized by $\mathrm{T}=\{$ Insert_outer_packaging $\}$ totaling 1 minute for the respective step. Once positioned, the cargo package is closed, this procedure takes 2 minutes to complete. At this time a check is performed by the ANAC, where it approves or disapproves the cargo, this procedure takes 5 minutes for each package. If ANAC disapproves any cargo $\mathrm{P}=\{$ ANAC_Inspection_Rejected $\}$, this cargo enters a rework process, where the entire procedure is performed from the beginning.

If the cargo is approved in the inspection step $\mathrm{P}=\{$ ANAC_Inspection_Accepted $\}$, this cargo is considered released. After this analysis process performed by ANAC, these cargos go to the place of finalized cargos and then are placed inside the aircraft, which activity is defined by the transition $\mathrm{T}=\{$ Positioning_cargo_on_aircraft $\}$, which requires 15 minutes to be performed. Once positioned at $\mathrm{P}=\{$ Positioned_Cargos $\}$, they go through a follow-up period, that is, supervised until they are dispatched to their final destination, this activity is represented by the transition $\mathrm{T}=\{$ Cargo_tracking_traceability $\}$ until they are dispatched $\mathrm{P}=\{$ Dispatched_cargos $\}$ shortly thereafter. The whole process if there is no rework, it takes 63 minutes.

A control structure, where it will check if the $T=\{$ Stop_Lack_Boxes $\}$ and $\mathrm{T}=\{$ Stop_Lack_Bottles 1$\}$ bottle stocks are empty, thus generating a deadlock or system crash, allowing the reason to be identified why the system stopped, whether it was for lack of $\mathrm{P}=\{$ Lack_Boxes $\}$ boxes or for lack of $\mathrm{P}=\{$ Lack_Bottles $\}$ bottles.

In parallel to this process, there is another structure where it will count the days of operation. The $\mathrm{T}=\{$ Count_Days $\}$ transition will only occur after 1,440 minutes (60 minutes $\times 24$ hours $=1,440$ minutes/day), so counting on $\mathrm{P}=\{$ Days_of_Operation $\}$ how many days were spent for the simulation to run. The $\mathrm{T}=\{$ Finish $\}$ transition where simulation is terminated if 10,000 loads are dispatched, thus marking an event at $\mathrm{P}=\{$ Finished $\}$, allowing it to be identified that the simulation deadlock occurred for this reason.

\subsection{Simulation}

By simulating a refueling structure for the model 1 Styrofoam boxes and Gelopet refrigerant elements. In this case there is a replenishment of boxes and a place for their storage. Every 1,440 minutes (equivalent to one day), two boxes are replenished, reaching the storage location that holds 1,000 boxes, when there is room for replenishment (assuming no more than the space can hold).

In order for the perishable elements to be maintained with quality, refrigerant material is required, so a certain number of units of this material are replenished within 1,440 minutes, which are then taken to the storage location which holds 4,000 units ( it is based on the premise that one cannot store more than space can hold). 
It was considered that replenishment should comply with primary logics such as: no more elements can be allocated than the stock can hold (eg. Gelopet bottle stock must comply with the limitation of 4,000 locally allocated bottles), so if the stock plus replenishment exceeds the limitation (the same will not happen); despite refueling, the days should pass, even if there is no service.

Following these assumptions, an administrative analysis that must be weighed is how, in contractual terms of suppliers, replenishments will be carried out, which can now be weighted by simulator-driven planning. The target value of 10,000 cargos dispatches was used as reference. With these references, Tab. 2 shows the results obtained.

In addition to the fact that the 10,000 shipments dispatched in 833 days, correspond to an investment in bottles (not counting labor, Styrofoam box etc.) of R $\$ 120,150.00$, where through the simulator, it is possible to evaluate if this is viable over a period of just over 2 years and 3 months or if a smaller investment is more prudent. It is worth noting that every change of behavior of the process is contemplated by the simulator.

Regarding the rework index, it can be seen that, by the data entered by the user, in the current scenario, it is within an average margin of $8 \%$, ranging from $\pm 0.5 \%$. It is up to the manager to assess, in the dispatch process, whether a reassessment is feasible and interesting if this loss rate is detrimental to the process.

Such a simulator addresses one of the most complex situations of this type of cargo: as it is a perishable load, the delay time during the dispatching process can be crucial. Such a cargo may be totally dependent on shipping time and may lose important properties if it has an improper storage time.

The structure can show, according to the number of days of the process, the time that can be spent on dispatch and the risk of delay. An example is the case where 10,000 cargos are dispatched in 833 days. Average load time is 12 loads / day (which means an average of about 0.5 loads per hour, meaning the load is being shipped on average 2 hours - this may or may not be beneficial to the company, depends on each cargo to be dispatched).

Some questions need to be considered as: there is no parameter of how many cargos will be shipped (should be estimated by the manager at the time of strategic planning); it is necessary to know the flow of the production process of the suppliers of boxes and bottles to abstract their interaction with the logistics process of the studied operator.

Table 2: Simulations

\begin{tabular}{|c|c|c|c|c|c|c|c|c|c|}
\hline $\begin{array}{l}\text { Box } \\
\text { Reload }\end{array}$ & $\begin{array}{l}\text { Bottles } \\
\text { Reolad }\end{array}$ & $\begin{array}{l}\text { Operatio } \\
\text { n Days }\end{array}$ & $\begin{array}{l}\text { Cargos } \\
\text { Received }\end{array}$ & Shipments & Reworks & $\begin{array}{l}N^{\circ} \text { of Boxes } \\
\text { Replenishment }\end{array}$ & of Bottless \\
Replenishment & $\begin{array}{l}\text { Simulati } \\
\text { on Time } \\
\text { (sec.) }\end{array}$ & $\begin{array}{l}\text { Stop } \\
\text { Cause }\end{array}$ \\
\hline 1 & 10 & 48 & 762 & 560 & 49 & 562 & 48 & 40 & $\begin{array}{l}\text { lack of } \\
\text { bottles }\end{array}$ \\
\hline 5 & 50 & 85 & 1227 & 1025 & 85 & 205 & 84 & 14.75 & $\begin{array}{l}\text { lack of } \\
\text { bottles }\end{array}$ \\
\hline 6 & 60 & 109 & 1512 & 1310 & 109 & 218 & 108 & 15.5 & $\begin{array}{l}\text { lack of } \\
\text { bottles }\end{array}$ \\
\hline 7 & 70 & 149 & 1997 & 1795 & 151 & 256 & 148 & 18.45 & $\begin{array}{l}\text { lack of } \\
\text { bottles }\end{array}$ \\
\hline 8 & 80 & 241 & 3102 & 2900 & 246 & 362 & 240 & 26.1 & lack of \\
\hline
\end{tabular}




\begin{tabular}{|c|c|c|c|c|c|c|c|c|c|}
\hline 9 & 90 & 328 & 4143 & 3943 & 329 & 327 & 352 & 25.4 & $\begin{array}{c}\text { bottles } \\
\text { lack of } \\
\text { boxes }\end{array}$ \\
\hline 10 & 100 & 491 & 6100 & 5900 & 489 & 490 & 473 & 35.5 & $\begin{array}{c}\text { lack of } \\
\text { boxes }\end{array}$ \\
\hline 20 & 100 & 833 & 10000 & 10000 & 827 & 500 & 801 & 60 & 10000 \\
\hline 50 & 100 & 833 & 10000 & 10000 & 827 & 200 & 801 & 60 & 10000 \\
\hline 100 & 1000 & 833 & 10000 & 10000 & 821 & 100 & 80 & 60 & 10000 \\
\hline
\end{tabular}

Source: (Authors, 2019)

Based on the modeling and structure developed, it is possible to make fundamental decisions in the process such as: deciding if there is a need to contract materials supply services; decide the hierarchy of materials and methods; decision of better flows and harnesses; prediction of impacts on the process due to certain decision making. Being able to simulate such decisions by obtaining agile and accurate answers is paramount because it is possible to stimulate the amount of financial resources to be invested, thus bringing a great degree of reliability and accuracy, enabling analysis and cost reduction.

\section{Conclusion}

This research demonstrates how an optimization can contribute to investments in sustainability (demonstrating the use of bottles that were discarded after use) and the use of modeling and simulation of decision-making processes.

The optimization provided the operator with savings, which over a year could reach almost half a million reais, with quality, time and temperature requirements respected and maintained.

The simulator developed, besides assimilating the required demands, can design future activities, with a tool available in the literature.

\section{References}

[1] Agência Nacional de Aviação Civil - ANAC. (2013). Transporte Aéreo Internacional de Carga. Estudo sobre Transporte Aéreo Internacional. Available in: http://www.anac.gov.br

[2] Cassandras, C.G. and Lafortune, S. (2008). Introduction to discrete event systems. Springer Science \& Business Media.

[3] Novaes, A. (2016). Logística e gerenciamento da cadeia de distribuição. Elsevier Brasil.

[4] Reis,T., Daryane J. and Souza, F.H.B. (2018). Discrete Events Systems For Controlling the Production Process in a Dairy Industry. XXXVIII Encontro Nacional de Engenharia de Produção. Maceió, Brazil, http://www.abepro.org.br/biblioteca/TN_STO_258_484_35879.pdf

Available

in:

[5] Sakurada, N. and Miyake, D.I. (2009). Aplicação de simuladores de eventos discretos no processo de modelagem de sistemas de operações de serviços. Gestão \& Produção, vol 16 , n. 1, p. 25-43. 
[6] Lisboa, A. C., De Souza, F. H., Ribeiro, C. M., Maia, C. A., Saldanha, R. R., Castro, F. L., and Vieira, D. A. (2019). On Modelling and Simulating Open Pit Mine Through Stochastic Timed Petri Nets. IEEE Access, vol. 7, 112821-112835. DOI: 10.1109/ACCESS.2019.2934718.

[7] Silva, R.C.T. (2017) Análise Crítica da Logística Aérea de Cargas Perecíveis: Estudo de Caso em um Operador Logístico (Unpublished Bachelor's Dissertation). Centro Universitário de Belo Horizonte UNIBH, Belo Horizonte, Brazil.

[8] Silva, R.C.T., Reis, A.V. and Souza, F.H.B. (2017) Análise Crítica da Logística Aérea de Cargas Perecíveis: Estudo de Caso em um Operador Logístico. Proccedings in Encontro de Saberes 2017 - Semana de Iniciação Científica. Ouro Preto, Brazil. ISSN: 2176-3410.

[9] Wang J. (1998). Stochastic timed petri nets and stochastic petri nets. In: Timed Petri Nets, Springer, pp 125-153. 